\title{
Successful Pregnancy Outcome in a Lady with Polyglandular Autoimmune Syndrome Type II
}

\author{
Munazzah Rafique and Devjani Das \\ Department of Obstetrics and Gynaecology, Wrexham Maelar Hospital, Betsi Cadwaladr University Health Board, North Wales, \\ United Kingdom
}

\begin{abstract}
We report a case of a lady who had polyglandular autoimmune syndrome type II (hypothyroidism, Addison's disease, vitiligo), who completed a successful pregnancy. Addison's disease (AD) was confirmed by the presence of anti-adrenal antibodies and hyponatremia. The patient had pre-pregnancy counselling about the need of antepartum, intrapartum and postpartum steroids. The pregnancy was managed with endocrinologist and obstetrician inputs, and appropriate follow-ups. Her pregnancy was completed with no complications. Labour was complicated by hyponatremia, secondary to nausea and vomiting that needed anaesthesia consultation. The patient delivered by vaginal delivery with no perinatal or early neonatal complications. The fetal growth was at $90^{\text {th }}$ centile.

Management in pregnancy, labour and postnatal period requires multidisciplinary care by the endocrinologist, obstetrician, midwife, anaesthetist and neonatologist.
\end{abstract}

Key Words: Addison's disease, Hypothyroidism, Hyponatremia, Labour, Pregnancy.

How to cite this article: Rafique M, Das D. Successful Pregnancy Outcome in a Lady with Polyglandular Autoimmune Syndrome Type II. J Coll Physicians Surg Pak 2022; 32(01):102-104.

\section{INTRODUCTION}

Addison's disease (AD), also known as primary adrenocortical insufficiency, is a rare endocrine disorder caused by autoimmune destruction of the adrenal cortex. ${ }^{1}$ The symptoms are non-specific unless acute adrenocortical insufficiency sets in. ${ }^{2}$ Diagnosis is made by autoantibodies. ${ }^{3}$ Treatment is based on continued care and maintaining the patient on standard replacement therapy of steroids. However, acute adrenal crisis should be treated as an emergency. ${ }^{4} A D$ may increase the risk of adverse maternal and neonatal outcomes during pregnancy; and there is limited evidence regarding its management. ${ }^{5}$

Moreover, its symptoms simulate the normal physiological changes in pregnancy and pose significant diagnostic challenges. ${ }^{6}$

\section{CASE REPORT}

A 29-year nulliparous lady was diagnosed with primary hypothyroidism in the past. She was on $125 \mu \mathrm{g}$ of thyroxine. A year later, she presented with symptoms of dizziness, headache and feeling unwell.

Correspondence to: Dr. Munazzah Rafique, Department of Obstetrics and Gynaecology, Wrexham Maelar Hospital, Betsi Cadwaladr University Health Board, North Wales, United Kingdom

E-mail: munazzahr@yahoo.com

Received: October 25, 2020; Revised: January 18, 2021; Accepted: April 25, 2021

DOI: https://doi.org/10.29271/jcpsp.2022.01.102
She had no family history of thyroid, adrenal or autoimmune disorders. On examination, there was pigmentation of her palmar creases, a patch of vitiligo over her antecubital fossa, and significant postural drop of blood pressure of up to 35 $\mathrm{mmHg}$. The relevant investigations are shown in Tablel.

Table I: Blood investigations at pre-pregnancy clinic.

\begin{tabular}{|c|c|}
\hline $\begin{array}{l}\text { Electrolytes: } \\
\text { Sodium: } 124 \mathrm{mmol} / \mathrm{L} \\
\text { (133-146) } \\
\text { Potassium: } 5.7 \mathrm{mmol} / \mathrm{L}(3.5-5)\end{array}$ & ACTH: 290 ng/L (7-63) \\
\hline $\begin{array}{l}\text { Short Synacthen Test: } \\
\text { Baseline Cortisol: } 27 \mathrm{nmol} / \mathrm{L} \\
\text { At } 30 \text { minutes Cortisol: } 29 \\
\text { nmol/L }\end{array}$ & $\begin{array}{l}\text { Plasma viscosity: } 1.58 \mathrm{mPa} \\
(1.50-1.72)\end{array}$ \\
\hline $\begin{array}{l}\text { Haemoglobin: } 89 \\
\text { g/dl (115-165) }\end{array}$ & $\begin{array}{l}\text { Serum Osmolality: } 273 \\
\mathrm{mmol} / \mathrm{Kg}(275-295)\end{array}$ \\
\hline $\begin{array}{l}\text { Thyroid function tests: } \\
\text { TSH: } 19.28 \mathrm{mU} / \mathrm{L}(0.35-5.50) \\
\text { T4: } 8.5 \mathrm{pmol} / \mathrm{L}(7.0-17.0)\end{array}$ & Urine Osmolality: $566 \mathrm{mmol} / \mathrm{Kg}$ \\
\hline Coeliac screen: Negative & GFR: $>90$ \\
\hline $\begin{array}{l}\text { Anti-adrenal antibodies: } \\
\text { Positive }\end{array}$ & $\begin{array}{l}\text { D21 Progesterone: } 2 \\
\mathrm{nmol} / \mathrm{L}(>28)\end{array}$ \\
\hline $\begin{array}{l}\text { Anti-ovarian antibodies: } \\
\text { Negative }\end{array}$ & HbA1C: $33 \mathrm{mmol} / \mathrm{mol}(20-41)$ \\
\hline
\end{tabular}

A diagnosis of AD was made and she was started on intravenous fluids and steroids. Following this, she was commenced on maintenance doses of oral hydrocortisone, $15-20 \mathrm{mg}$ and fludrocortisone, $0.05-0.20 \mathrm{mg}$, once daily.

The patient was on progesterone only contraception, which was stopped after pre-pregnancy counselling by the endocrinologist and obstetrician. She was counselled regarding the need to increase her steroids and levothyroxine in pregnancy, ante- 
natal appointments in maternal medicine clinic, along with the need for additional blood tests and for ultrasound scans for fetal growth monitoring. The maintenance dose of fludrocortisone was increased in view of latest blood results. She was also informed that her care in pregnancy would involve a multidisciplinary team.

She conceived spontaneously after coming off her contraception. Her first appointment at the maternal medicine clinic was at 11 weeks gestation. She was normotensive and her booking body mass index (BMI) was 28. The booking bloods were normal with a haemoglobin of $130 \mathrm{~g} / \mathrm{dl}$. Renal function tests, electrolytes and thyroid function tests were normal.

She was under joint care of the obstetric and endocrine teams. Her electrolytes and thyroid function tests were repeated 6-8 weekly, which were normal throughout pregnancy. The doses of hydrocortisone, fludrocortisone and levothyroxine did not need to be changed, as her blood levels remained stable throughout pregnancy. Serial growth scans were advised at 28, 32 and 36 weeks (Figure 1). There was a plan made by the endocrine team, for intravenous hydrocortisone in labour, with an initial dose of $100 \mathrm{mg}$, followed by $50 \mathrm{mg}$ every six hours till delivery.

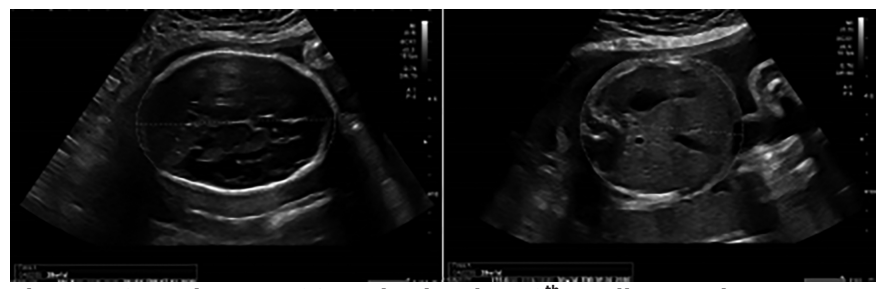

Figure 1: Growth scan at 28 weeks showing $90^{\text {th }}$ centile growth.

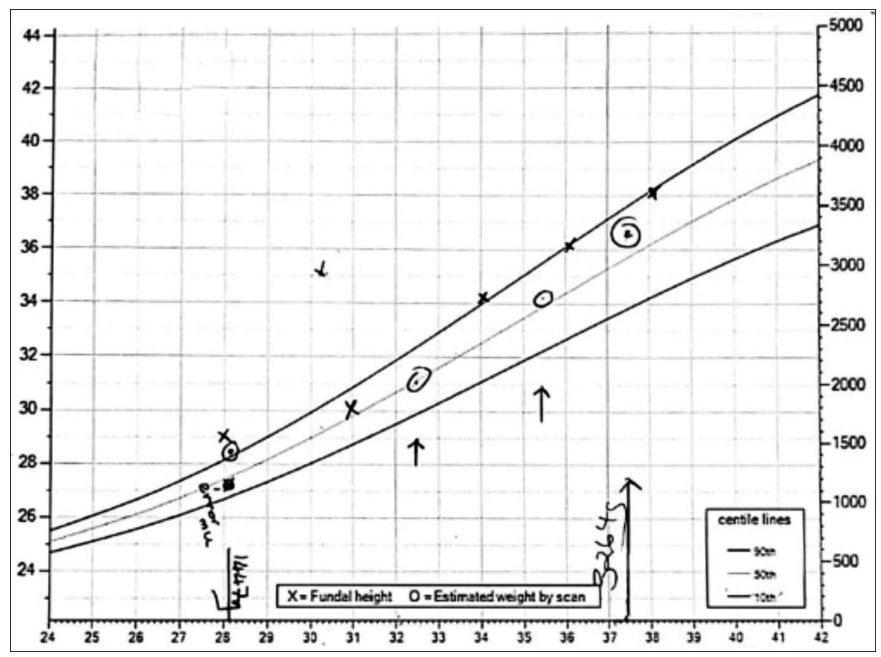

Figure 2: Customised growth chart with symphysio-fundal height (x) and estimated fetal weight (o) assessments.

Her pregnancy was uneventful, apart from intermittent episodes of light-headedness and fatigue at various times of the day. She did not seem to have had any episode of postural hypotension in the pregnancy. She had a glucose tolerance test (GTT) at 28 weeks gestation, which was normal. At 32 weeks' gestation, she was tested $\mathrm{HbAlC}$, which was $33 \mathrm{mmol} / \mathrm{mol}$ with non-diabetic range of $20-41$, according to NICE and local guidelines. The symphysio-fundal height on customised growth chart was on the 90th centile and the estimated fetal weight was reported as between 50th-90th centile (Figure 2).

The patient had two episodes of decreased fetal movement in 3rd trimester; and was induced after 38 weeks gestation. She was given intravenous steroids in labour as planned. She had an anaesthetic review in early labour. Analgesia in labour was discussed, and she decided to have entonox. A plan was made for monitoring fluid balance and electrolytes. The need for monitoring sodium levels was emphasised, especially as she was on oxytocin as part of the induction process.

She also developed nausea and vomiting in labour. She had abnormal electrolytes with a low sodium of $127 \mathrm{mmol} / \mathrm{l}$. She was reviewed by the endocrinologist and the dose of hydrocortisone was increased. Blood electrolytes were repeated 6-hourly in labour. She delivered by spontaneous vaginal delivery with an estimated blood loss of $583 \mathrm{ml}$. The baby was reviewed at birth by the paediatric team. A male baby of 3,360 gm was delivered at 39 weeks gestation with Apgar score of 9 and 10. During the first three days postpartum, she was given double the usual dose of her steroids, prior to going back to her pre-pregnancy doses. Repeat thyroid and renal function tests were normal. She was given a follow-up appointment with the endocrine team in 6-8 weeks.

\section{DISCUSSION}

AD has an incidence of 10-15 per 100,000, and is very rare in pregnancy. Itis an autoimmune condition. ${ }^{1,7}$ The clinical presentation is non-specific and high degree of clinical suspicion is required for diagnosis, which may be delayed in pregnancy.

Pregnancy itself has no effect on $A D$. However, during pregnancy there is a physiological increase in serum cortisol and cortisol binding globulins. ${ }^{5,6}$ Moreover, urinary excretion of cortisol also rises. There are no pregnancy specific reference ranges for cortisol and ACTH levels, which makes the diagnosis of the condition in pregnancy more difficult. Alow level of serum sodium and 09:00 am cortisol, raised ACTH and the short synacthen test are used for diagnosis of $A D$ in pregnancy. ${ }^{4,6,8}$

In autoimmune $A D$, maternal adrenal and 21-hydroxylase antibodies can cross the placenta, but they do not cause any fetal or neonatal adrenal insufficiency. ${ }^{5,8}$ Women with $A D$ are at risk of hyponatraemia and metabolic acidosis. ${ }^{9}$ The fetal risks with AD are the miscarriage, usually in the presence of antibodies, preterm delivery, growth restriction and intrauterine fetal death. ${ }^{10}$

Depending on the clinical and biochemical parameters, hormone replacement therapy with glucocorticoids and mineralocorticoids is needed in pregnancy, labour and postpartum period. $^{6}$ During pregnancy, glucocorticoid replacement is essential and the commonly used regime is multiple daily doses of hydrocortisone or cortisone acetate along with fludrocortisone. For a pregnant patient, the optimal glucocorticoid dosing scheme is not specified, but the need to change the dosage during gestation is expected. ${ }^{8}$ During the 24 th week, 
physiological rise in cortisol levels occurs that requires $20-40 \%$ increase in dose. ${ }^{8}$ The glucocorticoid of choice is hydrocortisone, as it does not cross the placenta. Monitoring is dependent on clinical observations, but becomes more difficult, as symptoms of excessive (striae, weight gain) or inadequate replacement (tiredness, nausea, vomiting) often present with very poor precision. ${ }^{8,9}$ Increment in dose is usually required during the third trimester. ${ }^{11}$ Few patients who develop persistent vomiting, especially in the first trimester, can be managed with an increased dose of steroids. ${ }^{5,11}$

This challenge was highlighted in current case as complaints associated with inadequate therapy doses were perceived as normal labour symptoms and not as warning signals. However, early involvement of multidisciplinary team helped in timely management and replacement therapy to prevent complications. Management in labourwas by intravenous doses of glucocorticoids.

Progesterone has anti-mineralocorticoid effects and, when its levels increase during pregnancy, a modification to the dosage of fludrocortisone may be appropriate and the increase in hydrocortisone dose during the third trimester may preclude this need. ${ }^{12}$ Pre-pregnancy doses are resumed after the delivery. ${ }^{12}$

No problems with lactation are encountered in the majority of cases. ${ }^{10,11}$ No increase in maternal mortality has been noted, if $A D$ in pregnancy is adequately treated.

Fetal outcomes are satisfactory in most cases because the fetus produces and regulates its own adrenal steroids and has normal serum electrolytes and adrenal activity. However, up to $30 \%$ of neonates may have adrenal cortical or 21 -hydroxylase antibodies. In this case, the baby was healthy and did not have antibodies.

\section{PATIENT'S CONSENT:}

The patient had given informed written consent to publish the data concerning this case.

\section{CONFLICT OF INTEREST:}

The authors declared no conflict of interest.

\section{AUTHORS' CONTRIBUTION:}

MR: Conceptualised the idea and took consent.

$\mathrm{DD}$ : Did the scientific input and proofreading.

MR, DD: Contributed to the case study and were directly or indirectly involved in this patient care, had collected the information and written the manuscript.

\section{REFERENCES}

1. Michels A, Michels N. Addison disease: Early detection and treatment principles. Am Fam Physician 2014; 89(7):563-8. PMID: 24695602

2. Charmandari E, Nicolaides NC, Chrousos GP. Adrenal insufficiency. Lancet 2014; 383(9935):2152-67. doi: 10. 1016/S0140-6736(13)61684-0.

3. Neto RA, de Carvalho JF. Diagnosis and classification of Addison's disease (autoimmune adrenalitis). Autoimmun Rev 2014; 13(4-5):408-11. doi: 10.1016/j.autrev.2014.01. 025.

4. Bancos I, Hahner S, Tomlinson J, Arlt W. Diagnosis and management of adrenal insufficiency. Lancet Diabetes Endocrinol 2015; 3(3):216-26. doi: 10.1016/S2213-8587 (14)70142-1.

5. Schneiderman M, Czuzoj-Shulman N, Spence AR, Abenhaim HA. Maternal and neonatal outcomes of pregnancies in women with Addison's disease: A population-based cohort study on 7.7 million births. BJOG 2017; 124(11):1772-9. doi: 10.1111/1471-0528.14448.

6. Kamoun M, Mnif MF, Charfi N, Kacem FH, Naceur BB, Mnif F, et al. Adrenal diseases during pregnancy: pathophysiology, diagnosis and management strategies. Am J Med Sci 2014; 347(1):64-73. doi: 10.1097/MAJ.0b013e31828aaeee.

7. Ten S, New M, Maclaren N. Addison's disease 2001. J Clin Endocrinol Metab 2001; 86(7):2909-22. doi: 10.1210/jcem. 86.7.7636.

8. Lebbe M, Arlt W. What is the best diagnostic and therapeutic management strategy for an Addison patient during pregnancy? Clin Endocrinol 2013; 78(4):497-502. doi: $10.1111 /$ cen.12097.

9. Lekarev O, New MI. Adrenal disease in pregnancy. Best Pract Res Clin Endocrinol Metab 2011; 25(6):959-73. doi: 10.1016/j.beem.2011.08.004.

10. Bjornsdottir S, Cnattingius S, Brandt L, Nordenstrom A, Ekbom A, Kampe O, et al. Addison's disease in women is a risk factor for an adverse pregnancy outcome. J Clin Endocrinol Metab2010; 95(12):5249-57. doi: 10.1210/jc. 2010-0108.

11. Langlois F, Lim DS, Fleseriu M. Update on adrenal insufficiency: Diagnosis and management in pregnancy. Curr Opin Endocrinol Diabetes Obes 2017; 24(3):184-92. doi: 10.1097/MED.0000000000000331.

12. Oliveira D, Lages A, Paiva S, Carrilho F. Treatment of Addison's disease during pregnancy. Endocrinol Diabetes Metab Case Rep 2018; 2018:17-0179. doi: 10.1530/EDM17-0179. 